\section{¿DIVINAS? MODA Y BLOGS DE MAQUILLAJE: MODELOS FEMENINOS}

\author{
Rocío Arana Caballero \\ Universidad Internacional de la Rioja \\ rocio.arana@unir.net
}

\section{DIVINE WOMEN? FASHION AND BEAUTY BLOGS: FEMALE MODELS}

Cómo citar este artículo/Citation: Arana Caballero, R. (2016). "¿Divinas? Moda y blogs de maquillaje: modelos femeninos". Arbor, 192 (778): a305. doi: http://dx.doi.org/10.3989/ arbor.2016.778n2008

Recibido: 08 septiembre 2015. Aceptado: 14 septiembre 2015.
Copyright: (c) 2016 CSIC. Este es un artículo de acceso abierto distribuido bajo los términos de la licencia Creative Commons Attribution (CC BY) España 3.0.
RESUMEN: Este trabajo pretende por una parte analizar cualitativamente dos libros recientes sobre moda, en una lectura paralela que compare modelos femeninos sacando conclusiones sobre ellos, y en segundo término realizar una breve panorámica de blogs de belleza. En la primera parte del trabajo, el análisis del reciente premio de ensayo Anagrama, iDivinas! Modelos, poder y mentiras (Soley-Beltran, 2015), que considera la identidad femenina como un travesti, una percha de usar y cambiar según intereses y situaciones, culmina en varios interrogantes: ¿es este el modelo de mujer actual? ¿Existe una esencia femenina?

Tras ello y como complemento, se desarrolla una breve panorámica de blogs de maquillaje, con cuatro calas en este universo, para intentar responder a una pregunta: ¿existe realmente una inquietud ética y estética detrás de estos espacios?
ABSTRACT: This paper aims to draw a qualitative comparison between two recent books on fashion, in order to attempt a parallel reading on female models, and secondly, provides a brief overview of beauty blogs. In the first part of the work, the analysis of the recent Anagram essay prize winner, iDivinas! Modelos, poder y mentiras (Soley-Beltran, 2015), which considers the female identity as a transvestite; as a coathanger to be used or changed depending on the interests and situations in hand, culminates in several questions: is this the model of the modern woman? Is there a female essence scent? The work also attempts to give a brief overview of beauty blogs to try to answer one question: are there ethical and aesthetic concerns behind these spaces?

KEYWORDS: Fashion; women; blogs; feminism; makeup. 
En mayo del 2015 apareció en el mercado un libro titulado iDivinas! Modelos, poder y mentiras, 43 premio Anagrama de Ensayo, que ha merecido una página en El Semanal de 2 de agosto de 2015. Un interesante ensayo autobiográfico femenino (motivos todos ellos de éxito), escrito por Patricia Soley-Beltran, antigua top-model catalana, hoy socióloga de una de sus universidades tras una fulgurante carrera en la moda y posteriores estudios universitarios en Inglaterra. Sobre el fondo negro habitual en la colección, la portada retrata una modelo ¿andrógina? con smoking blanco y pelo corto que posa desafiante para la posteridad.

Se da la circunstancia de que, años atrás, en 1988 otro libro sobre moda quedó finalista en el codiciado premio: La mística de la moda, escrito por la periodista Lola Gavarrón. Se impone entonces una lectura paralela y de corte sociológico sobre sus propuestas, aunque sin pretensiones de hacer un examen sistemático ni agotar las posibles consecuencias de una comparación muy rica en posibilidades. Y partiendo de supuestos obvios, mantenidos en los dos últimos siglos por la crítica especializada: la moda comporta identidad y valores (Figueras, 2009; Figueras, 2014), hace cultura (Alvira, 1988), está intrínsecamente ligada a las evoluciones de cualquier sociedad (Codina y Herreros, 2004). Ya Baudelaire en su Elogio del maquiIlaje (Le Figaro, 1863) apostaba por el artificio frente a la naturaleza y en ese sentido rompía una lanza por el maquillaje, desde los polvos de arroz a cualquier otro truco en pro de la belleza. Para él, la moda es un "síntoma del gusto por el ideal, que sobrenada en el cerebro humano por encima de todo lo grosero, terreno e inmundo que la vida natural acumula en él" (Baudelaire, 1863/2000, p. 1407). A comienzos del XX, Simmel (y en absoluto fue el único) advirtió en su Filosofía de la moda (1907) que había mucho de retrato psicológico y sociológico en ella a partir de la dinámica imitación / diferencia que la vertebra. En esta línea y en su Psicología del vestido (1964), Flügel aplica el psicoanálisis al vestido, como símbolo de sexo, ocupación y posición social. Y en La sociedad de consumo (2009), Baudrillard considera la moda como un fenómeno global (política, moral, sexualidad...) que estructura la sociedad de consumo, unida a la distinción social. De distinción habló mucho Bordieu: según él, la moda sería una lucha simbólica para mantener el estatus por parte de la clase alta; una estrategia de dominación vertida gota a gota -dirá en La distinción. Criterio y bases sociales del gusto (2006)-. Lipovetsky no acaba de coincidir con él: si así fuera -comenta¿cómo se incorporaría la autonomía personal propia de la moda a partir del XVIII?. Una autonomía in cres- cendo tras la caída de la Alta Costura (con ella sí tenía sentido la emulación propuesta por Bordieu), la aparición del prêt-à-porter con Pierre Cardin en 1959 y su famosa colección para Printemps de Paris, y el desarrollo de cadenas como Zara o H\&M... "que sin ser prêt-à-porter de lujo ni burdas imitaciones dejan espacio a la personalización, el chic y la elegancia" (De la Puente Herrera, 2011, pp. 164-165). Sea como fuere, detrás de estas y otras propuestas de los teóricos y al estudiar la moda, intencional o subrepticiamente estamos hablando de modelos de mujer, de iconos femeninos propuestos a las mujeres de a pie (Llovet, 2011, 9 de marzo). Estamos hablando de la mujer de cada época, con sus ilusiones y temores, con los retos que le plantea una sociedad en la que siempre quiso integrarse como ciudadana de pleno derecho. ¿Cuál fue su sitio? ¿Cuáles las expectativas generadas por ella misma y los demás hasta hoy?

Volviendo a los dos libros y perfilando su estudio desde esta perspectiva, se advierte cuánto ha cambiado el enfoque sobre la mujer de la modernidad a la posmodernidad. Cuando Ives Saint Laurent presentó su colección de 25 smoking femeninos con el consiguiente escándalo, tuvo buen cuidado de afirmar sus intenciones: "Nunca una mujer es capaz de aparecer más femenina que cuando viste ropa que no está destinada para ella. Por contraste su feminidad destaca más" (Figueras, 2009, p. 193). ¿Simple estrategia? Tal vez, pero en esas fechas las mujeres asaltaban la esfera pública desde esa feminidad que, en su afán de profesionalización, ya no correspondía solo al viejo rol de ángel del hogar, o al glamour de la mujer objeto. Y, escándalo sobre escándalo, de la mano de Chanel y otros se liberaban de los corsés que les impedían desarrollar sus nuevas funciones.

En contraposición a declaraciones así, las palabras de Patricia Soley-Beltran como personaje de su libro reflejan una de sus primeras y traumáticas experiencias como modelo:

Cual no fue mi sorpresa cuando, maquilladísima y vestida con un smoking blanco de corte impecable, me vi en pleno Paseo de Gracia barcelonés con un reputado fotógrafo gritándome que mirara a cámara con más y más fuerza, como si estuviera ojeando a un hombre al que quisiera conseguir. No me podía creer lo que me estaba pidiendo, pero era cierto. Me ordenaba una actitud abiertamente sexual, fuerte, casi predadora... (Soley-Beltran, 2015, p. 20).

Leídas a la luz de páginas posteriores, estas declaraciones pueden encuadrarse en la lucha de las top- 
model por reivindicar su trabajo y escapar al marchamo de "prostitutas" o mujeres fatales. Aun así, ¿por qué descartar algo de sinceridad en la jovencita apenas veinteañera que apuesta por una profesión aparentemente "aséptica" y se encuentra con algunas sorpresas? Porque sin ella saberlo, su smoking en el tercio final del siglo XX no tiene nada que ver con una identidad femenina que lucha por salir del rol de "ángel del hogar" e incorporarse como ciudadana a la sociedad, en igualdad de oportunidades con el varón. Eso quedó muy atrás y está registrado en la bibliografía de la segunda mitad del siglo por autores como el ya citado Lipovetsky, quien en El imperio de lo efimero (1990) define a ese tipo femenino como mujer patchwork: una mujer que reivindica la coquetería y el glamour femeninos, combinándolos con la destreza profesional. Lo que se plantea ahora a nivel teórico va mucho más allá y supone un crack, un corte radical con todo lo anterior. Escapa a los denominados "esencialismos de la mujer" para plantear el radical abandono de identidades binarias. El cuerpo ya no es masculino o femenino, sino un "constructo moldeable", una "identidad transversal"... Y es que, strictu sensu, no hay identidad sino "una percha para colgar los signos de la posible identidad" (Soley-Beltran, 2015 , p. 37) que, con algunas restricciones, pueden aplicarse a la mujer de hoy.

¿En esto culminaron casi dos siglos de lucha femenina por incorporarse a la sociedad?

Volvamos a los dos ensayos en pos de la identidad/ no identidad femenina.

\section{LA MÍSTICA DE LA MODA}

La mística de la moda, el libro de Lola Gavarrón, puede leerse como un clásico periodístico (fotos de las modelos incluidas). Estructurado en cinco capítulos ("La industria de la seducción", "El lenguaje del vestido", "El carácter orgánico del vestido", "La moda como liberación y ruptura de códigos" y "Rituales de moda. Salones y ferias"), parte de la alta costura, para delinear unos modelos femeninos glamourosos y objeto inalcanzable del deseo. En el prólogo están ya plasmadas muchas de las tesis que sustentará y reiterará entre líneas una y otra vez: el traje manifiesta el estado de ánimo de una persona. En definitiva, el objetivo confeso de su ensayo es ver cómo "la moda empieza a revelar en nuestro tiempo sus mecanismos y su sentido. El traje, que es su hilo conductor y su símbolo supremo, está cargado de significado. Este ensayo se propone desvelarlo" -dirá (Gavarrón, 1989, pp. 11-12)-.
Y es que vestirse, para ella y en su tiempo, "es todo un problema de identidad. De aceptarse y reconocerse uno tal y como se es" (Gavarrón, 1989, p. 14). Placer, conquista personal, el hábito hace al ánimo.

En el primer capítulo desarrolla cómo la seducción se ha convertido en industria nacional, en virtud de que la moda es el arte de lo superfluo necesario. En el segundo -asegura- el vestido es la concepción de sí mismo que se lleva sobre sí mismo: lo que nos hace civilizados frente al animal; supone una manifestación de poder, un lenguaje simbólico cargado de significado. Lo que no impide que la elegancia, el chic francés esté muy asociado a los desfiles, con su teatralización de la vida sobre todo para las 2.500 mujeres que consumen (en esas época) la alta costura. Gavarrón aprovecha para describir y sintetizar sumariamente las claves de los couturiers, los grandes de la alta costura: Balenciaga, Cardin, Dior, Courrèges, Givenchy, Grès, Molyneux, Patou, Rabanne, Ricci, Rouff, St Laurent, Schiaparelli, Ungaro, Chanel... mayoritariamente varones... Obviamente, la lista podría ampliarse. Son los inevitables en los diccionarios de moda (Rivière, 1996/2014), los que ya se fueron consagrando en exposiciones y museos, y pautaron los sueños femeninos. El clan se completa con diseñadores, modelos, publicitarios, árbitros de la elegancia, fotógrafos... Nombres que marcaron y marcan la moda en cada época. Una moda que la periodista rescata también a través de la literatura desde Baudelaire en adelante (Balzac, Mallarmé, Oscar Wilde o Proust).

Si la moda es estilo de vida, es indudable para la autora que el sentido estético junto al pudor y el sentimiento de pecado arrancan del vestido. Que en un segundo momento posibilita la introducción del teatro y el arte en la vida cotidiana. El capítulo tercero desarrolla ese tema a partir de Eugenia de Montijo y Worth quien fue uno de los primeros en diseñar para ella. Esta parte del ensayo concluye con un estudio del color desde Carlyle a Lacroix. Y enlaza con el capítulo cuarto, que glosa la moda como liberación y ruptura de códigos en el gran mundo galante: un ejercicio de humor y cultura frente a la carga social de vestirse.

"Rituales de moda. Salones y ferias" cierra como quinto capítulo dedicado al siglo XX lo que es un fenómeno distinto, la conversión de la moda en industria posterior a la segunda guerra mundial. El advenimiento del prêt-à-porter, el mundo de las pasarelas y el desfile, la guerra de ferias y diseñadores caracteriza el mundo actual, puro mercado efímero. 
Evidentemente, La mística de la moda no tiene las pretensiones ni el calado que alcanzará iDivinas! Se mueve en los parámetros habituales en la bibliografía (Seeling, 1999/2000) que estudia la alta costura como un fenómeno que permitió a las mujeres de a pie soñar y evadirse de las insatisfacciones cotidianas. Mujeres exquisitas inmortalizadas por el cine en comedias inolvidables como La costilla de Adán, Historias de Filadelfia, Atrapa a un ladrón. Modelos utópicos (lo normal no es lo que se ve en las pasarelas ni en el cine). Representan un plus de belleza que desde Aristóteles significó orden y simetría y desde Platón duplicó en nuestro mundo las esferas celestes. A partir del Renacimiento y hasta la modernidad fue trasunto de la belleza divina y, paralelamente, reflejo de la belleza interior del ser humano. Plantear la moda como retrato social... "fotografía de cada momento histórico, un flash capaz de sintetizar toda una época con su carga de aspiraciones, valores y contravalores" (Figueras, 2000a, p. 165), resulta coherente.

El ensayo de Gavarrón es eso: el estudio descriptivo de una serie de fenómenos que afectan a la mujer durante el pasado siglo, una época de cambios radicales que genera la rearticulación de funciones en la pareja. Pero, puestos a criticar, se queda corto: no ahonda ni se compromete desde el punto de vista antropológico... no arriesga nada que pueda ser políticamente incorrecto. Siempre ve los toros desde la barrera. Algo que no le sucede por ejemplo a Josefina Figueras, periodista con una trayectoria neta en el campo de la moda que dio lugar a varias publicaciones sobre sus protagonistas, especialmente españoles (Figueras, 2005 y 2011) a quienes ha entrevistado una y otra vez. Siempre apuesta por la mujer, desde cuya perspectiva enfoca el fenómeno "moda" en artículos como "La moda, un retrato social" o "La tiranía de la imagen" (incorporados como capítulos a su libro El feminismo ha muerto. iViva la mujer! Los desafíos de un siglo, 2000) y en libros como Moda y estilos de vida: el poder de la novedad (2014) y Moda y valores. El desafío de lo nuevo (2009). Imposible analizarlos ahora, alargarían en exceso el trabajo, pero por ejemplo este último es un libro de entrevistas propias y ajenas a los grandes creadores, consagrados o jóvenes. Casi como apéndice incorpora 25 entradas periodísticas de plumas variadas, siempre sugerentes y que enlazan con la presentación de la autora. Sus tesis son claras: en un mundo globalizado, la moda es un fenómeno apasionante y con valores bajo su frívola apariencia. Su variedad permite elegir a los consumidores según sus criterios y filosofía vital. Ha conseguido instalarse en los museos como un arte más (algo refrendado por los grandes creadores en las entrevistas que componen el libro) y, más allá de la tiranía del mercado consumista siempre alerta a lo nuevo, supone un valor estable, aunque sus dictados sean efímeros. La primera parte del libro es un cara a cara con los grandes (Elio Berhanyer, Adolfo Domínguez, Purificación García, Ágatha Ruíz de la Prada...). Y la última, apasionante desde el punto de vista sociológico, enfoca las trampas que le tiende el consumismo hedonista en el que vivimos inmersos. Sin contar, además, con distintos aspectos y valores relacionados con la moda, como

su difícil relación con los medios publicitarios, su compromiso ecológico y social, su vertiente antropológica que garantiza la dignidad humana, las señales inconfundibles de la elegancia verdadera y los contrasentidos del lujo de la era hipermoderna (Figueras, 2009, p. 12).

\section{2. ¡DIVINAS! MODELOS, PODER Y MENTIRAS}

Volviendo una vez más al punto de partida de este artículo: ¿qué tiene de interesante un ensayo en que una mujer entrevera su aventura vital, que arranca de la Barcelona del último franquismo y continua con estudios universitarios en el extranjero que la convierten en una académica? Más allá del atractivo de la escritura, del marco autobiográfico con el que suele abrir cada uno de sus cinco capítulos ("La bella y la bestia" (feminista), "Diosas de papel: de muñecas de cera a la übermodelo", “Una superficie profunda”, “¿Viva la diferencia?” y "Glamour, poder y silencio"), la clave está a la vista en las páginas del prólogo, que resumen a modo de sumario la experiencia de alguien deseoso de triunfar como modelo, como "una mujer del estilo de las que aparecían en las revistas: superfemenina, sexy y muy segura de sí misma" -dice (SoleyBeltran, 2015, p. 18)-. Frente al ensayo aséptico, más o menos distante de Gavarrón, el texto relata en primera persona el empeño de la jovencita por convertirse en mujer; un empeño con el que el lector (y más si es femenino) se identifica de entrada: "Lo intenté con considerable empeño, pero no lo conseguí" -continua diciendo (Soley-Beltran, 2015, p. 18)-. A lo largo de breves páginas culmina el relato de quien ha realizado su sueño y es ya una modelo exitosa. ¿Exitosa? Sí, pero descentrada como mujer y persona: la profesional parece ir desbancando a la mujer, cada vez más consciente de que su apariencia no es sino una ficción. Y una ficción equívoca frente a los cánones tradicionales: 
Aparentemente, ahora se me veía como a una andrógina tratando de ser una mujer real. Es decir, parecía una imitación de mujer. En suma, ni rastro de la auténtica supermujer que yo me había propuesto ser. ¿Por qué mi imagen no dejaba de causarme problemas, precisamente a mí, que tanto trabajaba para conformarme? Quizá la respuesta -como afirma la filósofa Judith Butler- sea que no hay original, que la mujer-mujer en la que yo trataba de convertirme es un ideal que realmente no existe (Soley-Beltran, 2015, p. 22).

Una declaración que remueve los cimientos de las esencias tradicionales, que apunta al auténtico objetivo del libro, trasunto de las investigaciones de su autora en torno a Butler y de más largo alcance que los objetivos explícitos: "Lo que a mí realmente me interesaba era indagar los procesos de definición, promoción, comercialización y manipulación de los patrones estéticos dominantes" (Soley-Beltran, 2015, p. 45). Es decir, quién mueve los hilos que dictaminan el ideal de feminidad encarnados en las top-model de éxito. $Y$ hacerlo además en carne propia, como aventura que implica y compromete la propia vida de la modelo, envejecida y quemada prematuramente por las estrategias de un mercado que usa y tira a los seres humanos. Si el ensayo interesa es porque afecta a la mujer de a pie: su protagonista está años luz de la antigua modelo glamourosa; es, por el contrario, el prototipo de la mujer actual. Una mujer desnortada que, tras superar una lucha de siglos por el derecho al voto y la ciudadanía, y alcanzar la independencia económica del trabajo retribuido en el marco de la igualdad, no acaba de encontrar su sitio en la sociedad. Una mujer que descubre (de la mano de la autora) que su cuerpo, medio de comunicación mediante el que obedecer o rebelarse frente a normas sociales, no es sino un símbolo, una metáfora social y personal: como ya se adelantó, "lo convertimos así en una percha donde colgar los signos de la propia identidad" (Soley-Beltran, 2015, p. 37). Y esta identidad es fluída, inestable, cambiante... en función del vestido, las modas, la manipulación publicitaria... "El acento en la plasticidad corporal nos insta a abordar el cuerpo como un artefacto maleable a producir, construir, desarrollar, refinar y perfeccionar, bajo nuestra propia responsabilidad" -dirá más adelante (Soley-Beltran, 2015, p. 198)-. No tendría sentido alguno plantear hoy la barrera baudelairiana entre lo natural y el artificio (Arancibia, 2009).

En consecuencia, este ensayo autobiográfico puede y debe leerse desde una óptica más globalizadora, en el marco de los posfeminismos que tratan de marcar distancias con los que denominan "esencialismos propios de la modernidad". No se trata de profundizar en la esencia. Tampoco de apuntar al smoking de St Laurent, símbolo de algo que sigue siendo un reto: la combinación de feminidad, poder intelectual y autonomía femeninas. Ahora, lo que según la escritora se propone a esa mujer desnortada es apoyarse en una herramienta, la metodología de género, para indagar en el problema central: ¿de qué depende saberse masculino o femenino? La propuesta de Patricia SoleyBeltran se concreta en estos términos: "la identidad de género, el saberse masculino o femenina, depende tanto de la biología como de complejos mecanismos colectivos de construcción cultural y de adhesiones personales a estos dispositivos" (2015, p. 173).

En las páginas siguientes del capítulo cuarto titulado "¿Viva la diferencia?”, se encuentra el centro, el eje escondido del ensayo, al fundir la experiencia personal de la autora con sus estudios, deudores de las teorías del siglo XXI, en concreto "el drag y la transexualidad como figuras que evidenciaban el género como el efecto de la materialización de normas culturales" -según Butler-. "¿Dónde situarme sin tener que renunciar a nada de lo que yo era?" -se pregunta la autora-. Porque

la idiosincrasia de un patrón, cualquiera que sea, limita el encaje de la gran diversidad de personas que existen y la complejidad personal propia (...). Tenía que aceptar mi identidad como relacional, despedirme de mis ansias de seguridad identitaria y de mis ilusiones de originalidad y plena autonomía (...). Yo era una persona atrapada en un cuerpo de mujer (SoleyBeltran, 2015, pp. 179-180 y p. 182).

Atrapada pero coqueteando con la androginia, como tantas modelos transgénero: "todas las personas podemos reconocernos en ese espejo ambiguo que no termina de reflejarnos" -afirma (Soley-Beltran, 2015, p. 185)-. Y continúa:

Dado que el ideal de género femenino a imitar es actualmente encarnado por modelos de moda, no es sorprendente hallar un número considerable de transexuales femeninas, de hombre a mujer, citadas como ideales de belleza femenina a los que aspiran (SoleyBeltran, 2015, 187).

¿No es sorprendente? El País (sábado 22, agosto 2015) incluye un reportaje sobre los primeros travestis de El Carrousel parisino ya octogenarios... Pero iuna golondrina no hace un verano! Ahora, entre líneas se desliza una propuesta muy fuerte, que rompe el modelo femenino de siglos dependiente de la 
biología y las costumbres. Una propuesta que se desglosa y sopesa (pros/contras) en el capítulo citado con afirmaciones arriesgadas: ... "la existencia latente de un deseo colectivo de flexibilizar la expresión personal de la identidad de género" (Soley-Beltran, 2015 , p. 183). Aunque, acto seguido parece contradecirse: "A mi entender, la estética del equívoco no alcanza a revisionar los códigos de género, sino que los reitera de otro modo. Podría decirse que, en las manos de la industria de la moda, ofreció una válvula de escape ritual al orden establecido" (Soley-Beltran, 2015, p. 188). ¿No será, más bien, que todavía existe un resto de sentido común en la sociedad y en mujeres que se saben más que manipuladas? ¿Y que en absoluto puede hablarse de ese supuesto y mayoritario "deseo transgenérico latente", a pesar de que la publicidad y la moda a partir del 2010 fuercen un cierto gusto por la denominada identidad transversal en actuaciones como las del modelo Andrej Pejic, que pasó de un campo de refugiados serbio a las portadas de Citizen $K$ travestido de mujer? ¿O que la agencia IMG Models haya fichado a Hari Nef como primer modelo transexual?

En su conjunto, el ensayo no está sólidamente fraguado (algo previsible por posmoderno), avanza y retrocede, va de lo autobiográfico a la tesis sociológica. Si este último aspecto alcanza su clímax en el capítulo cuarto, tras perfilarse en el prólogo y el primero, los restantes se centran en las topmodel: pasarelas, desfiles, anuncios publicitarios... Soley escritora respira por la herida de Soley protagonista de una manipuladora historia de modelos. Irrumpe así la gesta autobiográfica que, una y otra vez, se concentra y avanza en sumarios normalmente situados al inicio de cada capítulo -como ya se dijo-. La pregunta, reiterativa e insistente, es obvia: ¿por qué son tan divinizadas las top-model? ¿Qué glamour desprenden? En La tercera mujer (2002) Lipovetsky ya había advertido que "las estrellas, los modelos y las imágenes de pin-up, los modelos superlativos de feminidad salen del reino de lo excepcional e invaden la vida cotidiana" (p. 119). Asumiendo esto y lo efímero de la seducción del nuevo tipo femenino que triunfa en el $X X$, ¿qué estrategias de mercado las hacen todavía hoy tan deseables tras haberse convertido en "monstruos que eclipsaban todo y a todos los que las rodeaban y creían ser más importantes que el producto que debían promocionar" (Seeling, 1999/2000, p. 541) y ser cuasi repudiadas por su divismo en los noventa? Porque la tesis de la autora es rotunda: la imagen de las supermodelos es un gran engaño:
"SOY LO QUE QUIERAN QUE SEA" - dice en su autobiografía la maniquí francesa Dominique Abel -. Encarno el fantasma... dentro de la imagen. Aquello que no sobrepasa jamás la imagen (mayúsculas en el original). La modelo está inmersa en la fantasmagoría situada entre el producto y su significado simbólico (Soley-Beltran, 2015, p. 115)-.

Detrás, un montón de capas de identidad del modelo (amor, prestigio, maternidad, trabajo, sexualidad, etnia, nacionalidad, discriminación, erotismo, respetabilidad, hedonismo, disciplina... (Soley-Beltran, 2015 , p. 157). Las modelos son reflejo de nuestro tiempo, el reino de lo visible, y solo pueden aspirar a convertirse en una marca que no envejezca, gestionada por agencias que les dejan un estrechísimo margen de libertad.

El tema se había introducido desde el primer capítulo como objeto de estudio de la investigadora en Aberdeen, quien se cuestiona hasta qué punto las modelos rigen los ideales de belleza femeninos: "el ser o no ser modelo ¿estaba exclusivamente relacionado con las normas que regían la feminidad?" (Soley-Beltran, 2015, p. 39); e intenta desbrozar entre la persona trabajadora de una gran industria, y la máscara "divina" con su halo seductor. Algo superpuesto sobre seres mortales, a veces incluso acomplejados. Ello le da entrada para desarrollar en el siguiente capítulo ("Diosas de papel)" una historia de la moda desde las maniquíes, muy ligada a la evolución de los patrones sociales femeninos, que arranca de Worth, su mujer Vernet y Lucile, los responsables de las primeras modelos vivas y la puesta en marcha del desfile con su sello de espectáculo teatral que, inevitablemente mercantiliza el fenómeno de la moda. Desde 1924 Patou le añade el toque americano, influjo de la estética de los musicales y las chicas de revista. Una sociedad de consumo moderna acoge el triunfante reinado de las modelos, fruto de las conquistas de la flapper (autonomía y libertad personal a ritmo de charlestón, toque transgresor que genera ilusiones de sociedad menos clasista). El ralentizamiento en la ruptura de normas que supuso el crack no impidió el afianzamiento de la alta costura a fines de los cuarenta, desde el New Look de Dior que consolida a la mujer cosmopolita, sofisticada y de alto poder adquisitivo llevada al cine en la comedia americana de la época. Ni la llegada del prèt-à-porter veinte años después, con el triunfo de la minifalda y el canon estético de la juventud y modelos como Twiggy. Las revistas, fotografías y agencias de moda consolidan el despliegue mediático de las supermodelos, afir- 
madas como objeto de consumo; si bien fluctuantes, a tono con las modas (el jogging, o los tejanos, el minimalismo que Calvin Klein lanzara de la mano de Kate Moss a partir de los noventa, o "el atractivo de la fealdad" de la desangelada ropa "grunge" en el cuerpo de Kristen McHenamy).

Hoy la alta moda alterna con el mercado de masas. Las astronómicas cifras del mercado de lujo muestran el triunfo de la seducción en todas las capas sociales y en una sociedad en la que conviven tendencias contradictorias. En 2013 los beneficios anuales de la industria de belleza movían más de $\mathbf{2 0 0 . 0 0 0 ~ m i l l o n e s ~ d e ~}$ dólares; y se habló de 23 millones de operaciones de cirugía estética...

La autora recuerda que, tras el glamour y la aparente independencia de las maniquíes, se esconde la mercantilización a la que les someten las agencias, que eligen tipos étnicos determinados (caucásicos o waps), auténtico standard trasnacional que opera como dispositivo de neocolonialismo visual. El viejo vínculo entre etnia blanca, poder económico y superioridad sigue funcionando junto a la sobresexualización de la piel oscura, mestiza y exótica por cierto también de moda (no hay más que ver la portada del HOLA otoño 2015). Y como estrategias de mercado se ponen de moda la modelo madre o la self-madewoman (Naomí Campbell o Cindy Crawford), patrones de feminidad e iconos culturales que prueban es posible ser madre y una excelente trabajadora fuera del hogar. Si bien ese modelo positivo de comportamiento, que parecía destinado a redimir la posible imagen de mujer fatal asociada a las maniquíes, en los ochenta se va tiñendo progresivamente de connotaciones sexuales posando para revistas como Playboy o dejándose seducir por el estilo porno "zorrita" que parece imperar en el XXI, no sin violentas críticas y reacciones en contra.

Al terminar este breve repaso, se impone una reflexión que podría arrancar de una frase del ensayo de Soley-Beltran: "Las divinas beatificadas parecen haber reemplazado a los dioses que matamos con nuestras dudas" (2015, p. 217). ¿Merece la pena el trueque? Porque la mujer trabajadora o de clase media con escaso poder adquisitivo admiraba a las modelos, léase también estrellas de la pantalla, que parecían tenerlo todo: belleza, dinero y amor. Si la belleza fue promesa de felicidad de Stendhal en adelante y trampolín de movilidad social mediante el matrimonio, a todo ello se le suponía un modelo familiar y social estable, de identidades definidas en que el padre y la madre tenían su lugar reconocido.
La profesionalización femenina añadió el modelo de mujer independiente o empresaria: la belleza era interesante, pero no prioritaria para la profesional que concebía su vida en estos términos. Y al respecto, hay un par de acotaciones en el ensayo de Soley-Beltran que vienen al caso: al llegar a la universidad de Aberdeen para comenzar sus estudios tras su corta carrera de modelo, advierte:

Viví como una liberación el hecho de que mi físico no tuviera ninguna importancia para el trabajo intelectual. Así dejé atrás la arbitrariedad de las normas que rigen el comercio de la belleza para adentrarme en un ámbito donde el mérito está regido por criterios más transparentes y se premia el esfuerzo (SoleyBeltran, 2015, p. 27).

Primera impresión engañosa a largo plazo: a la doctora y conferenciante se le vuelve en contra su imagen física. ¿No es tremendo que todavía hoy de una mujer bella no se espere nada sólido intelectualmente hablando?

Al final de esa aventura autobiográfica trufada de pensamiento, dudas y búsqueda del sentido vital en un marco social ambiguo y posmoderno, quedan al menos dos interrogantes flotando en el ambiente: ¿Es posible hablar de verdad y belleza sin consumo en nuestro mundo actual? ¿Hay lugar para una ética responsable? Podría aventurar una respuesta curiosa a partir de un breve recorrido por ciertos blogs de maquillaje. No sin antes recordar un par de cosas: lo contradictorio de la moda es que universaliza pero también distingue... y en la distinción entra el decoro, con su doble vertiente ética y estética (Alvira, 1988, p. 51; Codina y Herreros, 2004). Eso por un lado. Por otro, que la moda ética gana terreno (Figueras, 2009; Figueras, 2014) y da lugar a toda una reconversión de tejidos, procesos de manufactura, estructuras económicas y logística de la distribución en pro de la sostenibilidad: estrategia y objetivo a la vez. Algo más que una moda, como pone de manifiesto Elena Salcedo en su libro Moda ética para un futuro sostenible (2014). Con plataformas como Slowfashionnext, dirigida por Gema Gómez. Y eventos como el BCN Ethical Fashion Festival (Cataluña, 2015), Andalucía de moda, coordinado por Pedro González, o el programa European Clothing Action Plan que recientemente ha dedicado 3,6 millones a reducir el impacto medioambiental. Sin olvidar que un grupo de 18 grandes distribuidores de fast fashion (moda rápida) acaba de firmar el proyecto The Social and Labour Convergence Project para corregir prácticas abusivas. 


\section{BLOGS, MAQUILLAJE, MUJER: ¿HAY ALGO MÁS?}

Y ¿qué ocurre con el mundo de la blogosfera? ¿Qué tienen que decir en él las mujeres?

El microclima creado en la red en torno a la belleza y el maquillaje parece contradecir las predicciones generales, que evidenciaban un claro retroceso del fenómeno blog frente al imparable auge de otras redes sociales más inmediatas. Enrique Baltanás lo acusaba en su propia bitácora con estas palabras:

En Twitter o en FaceBook, basta con una frase, una línea, ni siquiera eso, basta con una imagen o un enlace. Nada que ver con la, casi, siempre más dificultosa y arriesgada elaboración de una entrada. Porque una entrada puede ser un artículo, una página de un diario, una glosa, un microrrelato, un breve ensayo... Y eso, como se sabe, ya no está al alcance de cualquiera (Baltanás, 2011, 17 de julio).

Palabras que reconocían un mérito a los escritores de blogs, intimidad y posible calidad frente a inmediatez, y que confirmó el seis de septiembre del mismo año (2011) el articulista y poeta Enrique García-Máiquez en el diario La Gaceta:

El blog, por otra parte, preserva la intimidad de su autor, su espacio personal, sin sumirlo en la corriente continua de las redes sociales, en la vorágine de sus constantes y cambiantes mensajes (2011, 6 de septiembre).

Ambas referencias apuntan al hecho de que internet alberga una oportunidad de expresión personal y diálogo que, a pesar de su declive, merece la pena salvaguardar. $Y$ en el terreno de la mujer, el lector curioso se halla ante una horquilla que no ha perdido fuerza: la de las bitácoras personales que tratan en la red sobre belleza, cosmética, vida sana o maquillaje. Estos espacios, ya estén escritos por mujeres corrientes o por celebridades como Paula Echevarría o Sara Carbonero, han cobrado gran relevancia en los últimos tiempos, ya que el público femenino alterna su lectura con la de los artículos (on u off line) de revistas llamadas "de mujer", por cuestionado que esté tal marbete (Vogue, Telva, Elle, InStyle, etc...), convirtiéndose ambos en canales válidos para la formación e información sobre cuestiones estéticas.

Sin embargo, la pregunta que subyace ante la verdadera pléyade o sinfonía coral de mujeres que "se han lanzado al ruedo" de la escritura de un blog cosmético sería: ¿hay algo más? ¿Podemos rastrear un fondo cultural, ético y estético, de pensamiento incluso debajo de una fachada de color?
Se entiende, en primer lugar, que dicha fachada de color es algo meritorio, ya que esta sociedad está necesitada de dosis de evasión positiva tal como la entendía Tolkien: el famoso autor de literatura fantástica arremete contra los que critican la noble función de evasión que poseen los cuentos de hadas, defendiendo el halo poético y romántico que les rodea como motor inspirador esencial para la educación emotiva en la infancia (2012, p. 308). Mutatis mutandis, se puede cambiar el efecto de evasión que producen los cuentos por el que provocan los blogs cosméticos: en ese sentido apunta también la mítica frase de François Nars: "Diviértete, es sólo maquillaje", que reiteró en una entrevista para el suplemento Yo Dona (MontesFernández, 2008, 29 de septiembre), y que hoy en día puede parecer una obviedad, pero señala un aspecto lúdico y relajado de la cosmética que la aleja de los antiguos arquetipos machistas.

En efecto, hoy en día ninguna mujer concibe el acto de "pintarse ante el espejo" como un arma al servicio del goce masculino, sino más bien como un canal de expresión y a la vez de esparcimiento, casi como una liberación si se tiene en cuenta que el aspecto lúdico siempre es liberador. En la actualidad se utiliza el maquillaje para jugar, para gustar y gustarse, en definitiva para afirmar la identidad, no para esconderla ni someterla. En el mismo sentido se manifiestan famosos maquilladores como Peter Phillips, que al ser interrogado por Paloma Artola en el número de septiembre 2015 de la revista Telva acerca de cuál es la tendencia de belleza ahora mismo, responde: "el placer de maquillarte es una tendencia en sí, ahora las mujeres han perdido el miedo a hacerlo" (2015, septiembre, p. 182).

Volviendo a la cuestión planteada, ¿existe un trasfondo detrás de un blog de belleza?, su respuesta no es en absoluto afirmativa o negativa: el corpus es demasiado extenso, hay muchos tipos de blogs, autoras que escriben mejor o peor, que se documentan más o menos, que persiguen fines distintos. Pero sí que se pueden vislumbrar ejemplos claros de mujeres con formación universitaria e intereses muy diversos que utilizan su propio blog de belleza como plataforma o trampolín para expresar ideas que nacen del maquillaje y van más allá, que exploran lados convencionales o más desconocidos del feminismo o que protestan contra la cosificación de la mujer y, por qué no decirlo, del hombre.

Esto es así, puede ser así, los blogs de maquillaje tienen mucho que decir aparte del colorido de temporada, porque el maquillaje nos permite expresarnos: no en vano la sabiduría popular pregona que "el rostro es el espejo del alma". Precisamente en una 
entrevista afirmaba otro gran maquillador, Baltasar González Pinel, que la cosmética abre una grieta hacia nuestro mundo interior, y su objetivo es "elevar lo que dejamos ver de nosotros a través del rostro" (Arenas González, 2012, 18 de octubre). Y, escalando un peldaño más en sus reflexiones, enarbolaba el maquillaje como estandarte feminista que permite hoy en día expresarse a la mujer, lo que será avalado por otros como Óscar González Arenas:

¿Cómo defender una profesión que para muchos fomenta la esclavitud por el físico eternamente joven, eternamente perfecto, y a la vez ser fiel a mi más absoluta premisa, que es muy feminista, cercana y compartible? Me respondo: Para mí defender esta profesión, defender que queramos llevar maquillaje, es defender el instinto atávico por autodefinirnos, aceptarnos y celebrarnos (Arenas González, 2012, 18 octubre).

Sentadas ya las bases de que con un maquillaje o un blog sobre maquillaje la mujer puede (y debe) expresar mucho más, se exponen a continuación varios ejemplos concretos.

El más reciente puede ser la polémica que desató el catorce de abril de 2015 La tía Maruja en su blog, El blog de la tía Maruja, con motivo del nombre que había escogido la firma colombiana Masglo para bautizar los esmaltes de uñas de la colección "Aventura" (primavera/verano 2015). La mencionada bloguera, experta en márketing y conocida entre sus colegas de bitácora por su maestría en fabricar cosmética casera y en denunciar campañas poco éticas, comenzaba su post con estas líneas incendiarias:

Masglo acaba de lanzar una nueva colección de esmaltes de uñas con nombres que son denigrantes para la mujer. Esmaltes de uñas con nombre de putón verbenero. Han metido la pata hasta el fondo.

Dichos nombres son: Casquivana, Buscona y Muérgana. Los dos primeros aluden a la concepción o nuevo tópico de moda de mujer "zorrita", al que se ha aludido en el primer epígrafe de este artículo. Tras una consulta al Diccionario de la Real Academia de la Lengua Española, La tía Maruja reflexiona sobre la importancia de los adjetivos y del lenguaje:

Podréis decirme que lo importante es el producto en sí, no el nombre. Permitidme deciros que los nombres sí son importantes. A través de la verbalización, los pensamientos se materializan. El lenguaje es el primer medidor de cómo una sociedad interioriza los conflictos de género.
Y, desde su voz como experta en márketing, aconseja a la marca:

Retirad los productos a la de ya. Pedid disculpas. Ponedles otro nombre. Ponedles un número, lo que sea (...). Haced que vuestros trabajadores en Colombia se sientan orgullosos de fabricar vuestros esmaltes. Haced que vuestros comerciales se sientan orgullosos de vender vuestros esmaltes. Haced que yo, consumidora y bloguera, me sienta orgullosa de llevar vuestros esmaltes y de hablar de ellos (La tía Maruja, 2015, 14 de abril).

Este post tan reivindicativo tuvo repercusión en redes como Twitter y Facebook, incluyendo respuesta de la firma, y en otros blogs como El libro de conjuros de Tita Hellen... Bajo una fachada de color se esconde un concepto denigrante para la mujer, aunque del mismo modo se alza la voz desde este blog ante la cosificación del hombre, que también nos degrada a las mujeres ya que nos deja a expensas de un feminismo revanchista y materialista, mal entendido. Sucedió el nueve de agosto de 2013, ante las campañas orquestadas de la novedosa web Adopta un tío. Nos relata con asombro cómo el logo de la nueva web de citas muestra un icono femenino echando en un carrito de la compra a un icono masculino, como si fueran cien gramos de jamón de York, y reflexiona en torno al "hombre objeto":

Todo ello suena a hembrismo femichismo (siento el palabro, pero como el feminismo no es antónimo de machismo...). Si esto mismo se hubiera hecho al revés (si la que va al carrito es ella) seguro que el anuncio ya se hubiera retirado. (La tía Maruja, 2013, 9 de agosto).

Detrás de esta campaña gamberra, se agazapa un materialismo deshumanizado, ya que cataloga a los hombres que pueden encontrar las clientas en distintos marbetes y los define como productos. Concepciones que repugnan a la autora, que termina su post (un post ubicado, no hay que olvidarlo, dentro de un blog supuestamente "de maquillaje", con quintaesencias antropológicas:

Pero en este caso el "producto" es una PERSONA, esa que vas a "adoptar" y que vas a meter lo mismo en tu cama y puede que en tu vida. En el amor no hay sujetos y objetos: en una pareja sana ambos miembros son sujetos de la historia. Nadie adopta a nadie, nadie es la mamá de nadie, nadie echa en el carrito a nadie. (La tía Maruja, 2013, 9 de agosto).

El sintagma "hembrismo femichismo" es un neologismo que en buena parte no ha inventado La tía 
Maruja. Han corrido ríos de tinta en torno al primer término del binomio, "Hembrismo", y no es este el lugar para debatirlo, pero sí de hacer constar que hoy en día también se trata sobre él en la esfera de los blogs de belleza.

Y entre otras lo hace Hellen, autora del espacio El libro de conjuros de Tita Hellen. Trabajadora social y experta melómana, Hellen reivindica el título de "friki" como algo que la define y que no es en absoluto negativo, así como su derecho a reflexionar a partir de las cosas más sencillas y bellas de la vida, como el maquillaje. Lo más característico de esta bitácora es su forma de utilizar una tradición ya establecida, es decir, las originales manicuras que cuelga en él cada domingo como trampolín para hablar de diversos temas, focalizados en la mayoría de ocasiones en el feminismo. Se imbrican de esta manera creación y reflexión, maquillaje y pensamiento, por la sencilla fórmula de explicar a los lectores cuál ha sido la inspiración que provoca un determinado look. El maquillaje en muchas ocasiones es juego, pero ese juego tiene un "por qué", un motor... y una mujer se puede pintar los labios de rosa en octubre para solidarizarse con las afectadas del cáncer de mamá, por buscar un ejemplo.

El nueve de noviembre de 2014, tras mostrar sus uñas maquilladas, Tita Hellen opina sobre una diatriba muy actual en la blogosfera: en este entorno se está debatiendo de manera no formal la tendencia a no depilarse o a no maquillarse que adoptan algunas mujeres como presunta liberación, a lo que ella opone la idea de que la higiene y la creatividad son cualidades muy femeninas y pueden serlo también muy feministas:

Cuando una mujer me dice que no debo depilarme o no debo maquillarme o no puedo vestir de una manera u otra porque es el imperio falocéntrico el que me lo propone, yo sólo pienso en que mis piernas sin depilar se deshidratan más y pican (y mucho), en que me gusta ver colores imposibles en mi cara, porque soy así de rara y en que un día me gusta el negro y otro día el rojo, y otro el morado y ahora... me siento mejor con el rosa.

Nunca me he vestido como un hombre me ha pedido (ni siquiera mi padre, mi madre me decía "ni caso a tu padre, ponte lo que quieras"), sino como me he sentido cómoda y me han apoyado en ello. Eso también es feminismo.

Para apoyar estas líneas, la autora del blog recomienda la lectura del libro Bad Feminist de Roxane Gay. Y, al hilo de esta sugerencia, señala:
Hay muchas feministas que piensan que ser mujer es volver a las raíces y abrazar costumbres de tíos, como no depilarse, no maquillarse, poder ir con pantalones (...). El feminismo no es hembrismo, el feminismo no es revanchista, también lucha por derechos masculinos, busca que la igualdad sea total, y sabe que en esa lucha el hombre está invitado y es necesario (Tita Hellen, 2014, 9 de noviembre).

Así, el blog de belleza puede utilizarse, además de su uso habitual, para denunciar una campaña, una mala interpretación del feminismo, o incluso para reivindicar el mítico "porque yo lo valgo" revisando la imagen de L'Oreal a través de los tiempos, como hizo María Sánchez Zubizarreta en el blog Mil caprichos. Gracias a su entrada del día dieciocho de octubre 2010, las lectoras aprenden (o recuerdan) que la autora de este afortunado slogan fue Ilon Specht, copywriter de la agencia, y que surgió en un momento de rabia creadora.

Because I'm worth it arrasó. Poco importó qué proponía aquella campaña. Las ventas se dispararon y L' Oreal se fue consolidando, no como una marca para las mujeres, sino como la marca de las mujeres. Pasó a ser dueña y señora del nicho de tintes y, en 1997, la marca convirtió el slogan en seña de identidad de toda la compañía. La fuerza comunicativa de estas palabras es hoy día incuestionable y podemos decir que L'Oreal es Porque yo lo valgo (con más de un $80 \%$ de reconocimiento de marca.) (...). Aquella campaña tuvo como origen la semilla del feminismo, el choque entre una forma de pensar establecida y unas mujeres que reivindicaban públicamente su lugar y su papel socio-cultural. (María Sánchez Zubizarreta, 2010, 18 de octubre)

$\mathrm{Y}$, con versatilidad, en el mismo espacio se puede protestar como mujer contra la barbarie del aborto: el nueve de marzo de 2009 , en un momento social crítico (de fondo, una ley en la que las niñas de 16 años podían abortar sin consentimiento paterno), la otra escritora del blog Mil caprichos, Kitty, se expresaba así:

Mi blog a veces es frívolo, no me voy a engañar, pero ante las barbaridades que se suceden en España no puedo quedarme callada. [...] NO AL ABORTO. NO A LA MANIPULACIÓN. NO AL FEMINISMO MAL ENTENDIDO.

Si las niñas de 16 años pueden abortar sin consentimiento paterno... ¿ ¿por qué no pueden votar? ¿Por qué no pueden beber alcohol de más de 23? ¿Por qué no pueden fumar? 
Me parece que no me equivoco si digo que los efectos de un aborto en la mujer son brutales. Hay miles de estudios que lo demuestran. [...]

Ayudar a las mujeres a tirar adelante un embarazo no es fácil y los medios económicos para hacerlo no son precisamente extensos. Es muy fácil matar el "problema" y olvidarse de las mujeres (Kitty, 2009, 9 de marzo).

En la entrada siguiente, Kitty habla de las nuevas propuestas de Ikea. Y en la siguiente, enumera diversos balnearios para hallar un poco de relax. ¿Frivolidad? No: versatilidad. Porque en su día a día, la mujer del siglo XXI se desdobla en muchas mujeres distintas, trabajadora, superwoman, mamá, compradora compulsiva... todo cabe en ese nuevo continente que es el blog de belleza.

Por último, se presenta en este artículo un ejemplo algo diferente de reflexión en torno al papel de la mujer: se trata del vídeo Wo-man's world, un trabajo compartido por tres prestigiosas blogueras y que transmite un mensaje algo más aferrado al lenguaje feminista convencional, pero con tintes originales y hasta poéticos.

Subido a YouTube el 14 de febrero de 2011, fue fruto de la colaboración entre Miss Potingues del blog Miss potingues, Gadirroja de La Pinturera y Adriana de Colourful randomness. El mencionado trabajo es la respuesta de estas tres prestigiosas bloggers a un concurso organizado por la reconocida periodista de belleza y bloguera a su vez Inma López de Beauty victim. Dicho certamen tenía por título y reto las palabras "Tu lado masculino", y se invitaba a reflexionar a las bloggers participantes sobre cómo explorar el lado masculino de una mujer. El concurso giraba en torno al maquillaje, pero estas tres autoras van más allá. En un trabajo de cooperación grabaron un vídeo, con guión de Miss Potingues, montaje de Gadi- rroja y vestuario y maquillaje de Adriana, en el que se preguntan: ¿Y cuál es ese lado? ¿Mandar? ¿Por qué es eso masculino?

En la escena, y con un fondo musical en el que se escucha el mítico tema "It's a man's, man's, man's world" de James Brown, se ve a una mujer (Gadirroja) vestida de traje de chaqueta, lo cual entroncaría con la portada del libro de Soley-Beltran y con el comienzo del presente artículo... pero no, ya que mientras se viste "de hombre", la protagonista del vídeo Woman's world está maquillándose labios y uñas de rojo. En seguida aparecen las leyendas escritas a modo de subtítulos que narran la trama del vídeo (no hay voces ni más sonido que la música). Todo comienza con un "Pareces un hombre", una frase que la protagonista ha tenido que oír debido a su estilo de vida, algo que se desarrolla en los siguientes fotogramas: "No tienes expectativas de mujer, no eres sumisa, no tienes intención de renunciar a tu carrera, sino que sabes y te gusta mandar". Mientras la aludida responde, también por medio de subtítulos, se le ve saliendo a la oficina, tomando su cartera de trabajo, jugando a las cartas... y explicándose: "Soy ambiciosa, me gusta mi trabajo, me gusta el poder y no me avergüenzo por ello". El vídeo termina con una frase antológica que rebaja un poco la tensión aportando un toque poético:

Aunque vista un traje chaqueta, no hay reino que no se pueda gobernar con un tacón, y hoy el mundo necesita los míos (Miss Potingues, 2001, 14 de febrero).

Tras exponer esta pequeña muestra, parece acertado aventurar que existe en las redes un grupo de mujeres emprendedoras, cultas e inquietas que no renuncian a gustarse y gustar por medio del maquillaje, que no necesitan huir de su feminidad para reafirmarse, pero que utilizan sus bitácoras no solo como armas de color, sino como armas para mejorar el mundo que les rodea.

\section{BIBLIOGRAFÍA}

Alvira, R. (1988). Análisis filosófico de la moda. En Homenaje a Alfonso Candau. Valladolid: Universidad de Valladolid, pp. 47-57.

Arancibia, J. M. (2009). Maquillaje. (La apariencia: iniciación de correspondencias en Charles Baudelaire). A Parte Rei, revista de filosofía, 65. Disponible en http://serbal. pntic.mec.es/ cmunoz11/arancibia65.pdf

Arenas González, O. (2012, 18 octubre). Baltasar González Pinel (I). En Bôgart Make up [En línea]. Disponible en http://bogartmakeup. com/2012/10/baltasar-gonzalez-pinel-i/
Artola, P. (2015, septiembre). Entrevista a Peter Phillips. Telva, p. 182.

Baltanás, E. (2011, 17 julio). Sobre la primera crisis de los blogs. Al margen de los días [En línea]. Disponible en http:// almargendelosdias.blogspot.com. es/2011/07/sobre-la-primera-crisis-delos-blogs.html

Baudelaire, C. (1863/2000). Elogio del maquillaje. En: Millán Alba, J. y Prado Biezma, J. del (eds.) Charles Baudelaire. El pintor de la vida moderna (1863).

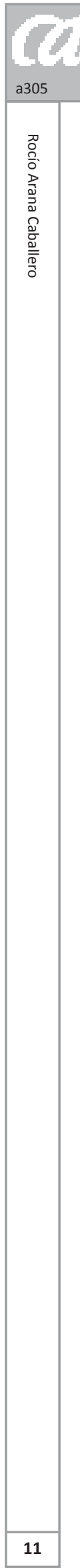

Baudelaire. Poesía completa. Madrid: Espasa Calpe, pp. 1405-1414. (e. o. Le Figaro, 26 y 29 de noviembre y 3 de diciembre de 1863).

Baudrillard, J. (2009). La sociedad de consumo. Sus mitos. Sus estructuras. Madrid: Siglo XXI.

Birlanga Trigueros, J. G. (2007). Baudelaire y la moda. Notas sobre la gravedad de lo frívolo. Revista Bajo Palabra, 2, pp. 13-21. 
Bordieu, P. (2006). La distinción. Criterio y bases sociales del gusto. Madrid: Taurus.

Bravo, Á. (2014). Nefertiti también usaba mascarilla. Fórmulas y elixires: cosmética y belleza a través de la historia. Madrid: Nowtilus.

Codina, N y Herreros, M. (eds.) (2004). Mirando la moda: once reflexiones. Madrid: Ediciones Internacionales Universitarias.

De la Puente Herrera, I. (2011). El imperio de la moda. Sevilla: Arcopress.

Figueras, J. (2000a). La moda, un retrato social. En: El feminismo ha muerto. iViva la mujer! Los desafíos de un siglo. Madrid: Ediciones Internacionales Universitarias, pp. 166-193.

Figueras, J. (2000b). La tiranía de la imagen. En: El feminismo ha muerto. iViva la mujer! Los desafíos de un siglo. Madrid: Ediciones Internacionales Universitarias, pp. 194-223.

Figueras, J. (2005). Protagonistas de la moda. Madrid: Ediciones Internacionales Universitarias.

Figueras, J. (ed.) (2009). Moda y valores. El desafio de lo nuevo. Madrid: Ediciones Internacionales Universitarias.

Figueras, J. (2011). Moda española: una historia de sueños. Madrid: Ediciones Internacionales Universitarias.

Figueras, J. (2014). Moda y estilos de vida: el poder de la novedad. Madrid: Ediciones Internacionales Universitarias.
Flügel, J. C. (1964). Psicología del vestido. Buenos Aires: Paidós.

García-Máiquez, E. (2011, 6 de septiembre). La literatura de calidad encuentra un nuevo género en los blogs. La Gaceta, p. 34.

Gavarrón, L. (1989). La mística de la moda. Barcelona: Anagrama.

Gay, R. (2014). Bad feminist. Nueva York: Harper Millenial.

González, A. M. y García, A. N. (eds.) (2007). Distinción social y moda. Pamplona: Eunsa.

Lipovetsky, G. (1990). El imperio de lo efimero. Barcelona: Anagrama.

Lipovetsky, G. (2002). La tercera mujer. Barcelona: Anagrama.

Llovet, C. (2011, 9 de marzo). Iconos de la moda ficticios con efectos reales. Aceprensa. Disponible en https://www. aceprensa.com/articles/iconos-de-lamoda-ficticios-con-efectos-reales/

Montes-Fernández, M. (2008, 29 de septiembre) Ante todo soy un creador. Entrevista a François Nars. Yo Dona. [En línea]. Disponible en http://www. elmundo.es/yodona/2008/09/29/ moda/1222683496.html

Rivière, M. (1996/2014). Diccionario de la moda. Los estilos del siglo XX. Barcelona: De Bolsillo.

Salcedo, E. (2014). Moda ética para un futuro sostenible. Barcelona: Gustavo Gili.
Seeling, Ch. (1999/2000). Moda. El siglo de los diseñadores 1900-1999. Köln: Könemann.

Simmel, G (1907/2014). Filosofía de la moda. Madrid: Casimiro Libros.

Soley-Beltran, P. (2015). iDivinas! Modelos, poder y mentiras. Barcelona: Anagrama.

Tolkien, J. R. R. (2012). Sobre los cuentos de hadas. En: Cuentos desde el reino peligroso. Barcelona: Minotauro, pp. 279-345.

\section{Recursos de Internet}

Tita Hellen. El libro de conjuros de Tita HeIlen. [En línea]. Disponible en http:// conjuracioneshellenisticas.blogspot. com.es/

Adriana. Colourful randomness. [En línea]. Disponible en http://www.colourfulrandomness.com/

Gadirroja. La Pinturera. [En línea]. Disponible en http://www.lapinturera.com/

La tía Maruja. El blog de la tía Maruja. [En línea]. Disponible en http://latiamaruja. blogspot.com.es/

María Sánchez Zubizarreta y Kitty. Mil caprichos. [En línea]. Disponible en http:// www.milcaprichos.com/

Miss Potingues. Miss potingues. [En línea]. Disponible en http://miss-potinguesweb.blogspot.com.es/ 